\title{
Characterisation of Arbequina Extra Virgin Olive Oil from Uruguay
}

\author{
Ana Claudia Ellis ${ }^{1} \&$ Adriana Gámbaro ${ }^{1}$ \\ ${ }^{1}$ Área Evaluación Sensorial, Departamento de Alimentos, Facultad de Química, Universidad de la República \\ (UdelaR), Montevideo, Uruguay \\ Correspondence: Ana Claudia Ellis, Área Evaluación Sensorial, Departamento de Alimentos, Facultad de \\ Química, Universidad de la República (UdelaR), Montevideo, Uruguay. E-mail: acellis@ fq.edu.uy
}

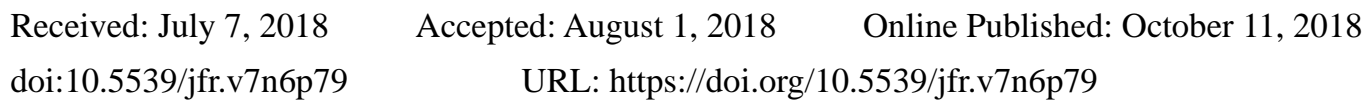

\begin{abstract}
Since the year 2002, the Uruguayan oil-producing sector has been growing at a steady peace, utilizing over 10,000 seeded hectares across the country. The aim of this study was to characterise both the chemical and sensory properties of the extra virgin olive oil variety known as Arbequina through two consecutive harvests. The work was carried out using olives with three different ripening indices; the oil was extracted using an Abencor system. The moisture of the olive, yield extraction, and yield on both a dry and wet basis were determined. The obtained oils were characterized by determining the free acidity, main antioxidant compounds (polyphenols and tocopherols), composition of fatty acids, and sensory profiles. Olive moisture was over 57\%, which led to production of pomaces characterized as "difficult pastes", explaining the low yield obtained. The harvest year and ripening index affected different parameters such as Abencor yield and, on a dry basis, the free acidity, polyphenolic content, oleic acid, and linoleic acid contents and fruity, bitter, and pungent intensities. To determine the best time of harvest, it is important to consider the balance between yield (which is significantly greater in olives with a ripening index above 3 ) and oil quality, as a higher ripening index decreases positive sensory attributes such as pungency and bitterness intensities.
\end{abstract}

Keywords: Arbequina, chemical characterization, sensory profile, virgin olive oil

\section{Introduction}

Extra virgin olive oil (EVOO) is a remarkably valuable product that is traditionally produced in Mediterranean countries; $95 \%$ of the world's olive oil is produced in Spain (Amelio, 2016; Reboredo-Rodríguez et al., 2016; International Olive Council [IOC], 2017). The olive habitat is concentrated at latitudes between $30^{\circ}$ and $45^{\circ}$, both in the southern and northern hemispheres in Mediterranean climatic regions (which is characterized by dry and warm summers and winters with mild temperatures) (Civantos, 2008; Navarro \& Parra, 2008; Rapoport, 2008).

Olive oil production has spread in recent years to beyond the Mediterranean region to non-traditional areas (Uruguay XXI, 2013; Villamil \& Conde, 2013; Rondanini, Castro, Searles, \& Rousseaux, 2014; Katsoyannos et al., 2015; Xiang et al., 2017). This spreading requires the adaptation of olive plants to new climatic conditions (temperature, precipitation, and moisture, for example) associated with latitudes and altitudes differing from those corresponding to the autochthonous regions of olive. Because of this adaptation, oil produced in these regions may differ in quality and composition from those produced in autochthonous regions (Romero, Saavedra, Tapia, Sepúlveda, \& Aparicio, 2016).

Uruguay is located between latitudes $30^{\circ}$ and $35^{\circ}$ which have a mean annual temperature of $17.7^{\circ} \mathrm{C}$ and mean annual rainfall of 1200-1600 mm (Instituto Nacional de Investigación Agropecuaria [INIA], 2017). In recent years, the production of EVOO has steadily increased from 112,000 kg in 2011 to 900,000 $\mathrm{kg}$ in 2017 (Asociación Olivícola Uruguaya [ASOLUR], 2017).

Arbequina is a cultivar typical of the Spanish region of Catalunya (Terragona and Lérida) and of Alto Aragón. It adapts easily to new environmental conditions and, because of its small size, precocity, high oil yield, good oil quality, and other agronomic characteristics, is particularly fit for new high-density olive orchards and mechanised cultivation (Rondanini, Castro, Searles \& Rousseaux, 2011; Yousfi, Weiland \& García, 2013; Borges et al., 2017). Furthermore, Arbequina olive oil is highly appreciated for its mild taste and is considered ideal for new and emerging markets compared to other oils, which can be more bitter and pungent (B. Jiménez \& Carpio, 
2008; Borges et al., 2017). Because of these positive factors, countries in South America have begun producing Arbequina, including Chile (García-González, Romero \& Aparicio, 2010), Argentina (Torres et al., 2009), and Brazil (Borges et al., 2017). In Uruguay, this cultivar has been cultivated in the past decade and now occupies the largest growing area (51\%) and is present in most national plantations (Uruguay XXI, 2013).

The chemical composition of EVOO is influenced by the olive cultivar, pedoclimatic conditions, geographical site, and ripeness stage. Several studies have shown that the choice of the optimal harvest period is essential for obtaining high-quality virgin olive oil (VOO) (Franco, Sánchez, De Miguel, Martínez \& Martín-Vertedor, 2015). During ripening, many metabolic processes occur which significantly affect the physical properties, chemical composition, and enzymatic activity of the fruit, which are reflected in the composition and quality of VOO (Lukić et al., 2017). Thus, it is important to determine the best harvest period for each variety to optimize olive productivity and ensure quality (Youssef et al., 2010, M. Beltrán, Sánchez-Astudillo, Aparicio \& García-González, 2015). Furthermore, according to B. Jiménez, Sánchez-Ortiz, Lorenzo, \& Rivas (2013) and Katsoyannos et al. (2015), as fruit ripening progresses, oxidative stability is reduced because of the decreased total polyphenol content in the ripe fruits.

Previous studies in the Mediterranean region examined modification of the major and minor components in different oil varieties during the ripening process. For example, Franco et al. (2015) evaluated the influence of ripening index (RI) on oil yield, olive moisture, fatty acids, and sensory attributes such as fruity, bitter, and pungent indices of seven varieties from the southwest of Spain, including Arbequina. Currently, Spain shows an increased RI of between 2 and 3 for Arbequina and Picual, indicating very good oil quality and high yield (Franco et al., 2015).

Few studies have examined how geographical and climatic conditions and ripening index affect the properties of Arbequina olive oil produced in Uruguay. Thus, the aim of the present study was to characterise both the chemical and sensory attributes of the EVOO variety Arbequina, considering different RIs, over two years of harvest.

\section{Materials and Methods}

\subsection{Plant Material}

\subsubsection{Samples}

The olives were supplied by five different olive plantations located in the southeast and southwest regions of the country throughout the time of the harvest study in years 2015 and 2016.

The selected olive trees for each producer were approximately the same age of eight years at the beginning of the study. For each sampling, trees were divided into two blocks of six trees each. First, a representative sample of $10 \mathrm{~kg}$ was hand-picked from both blocks. The sampling protocol was previously established, which specified that olives were to be picked from all four sides of the tree from different heights, starting from the outside of the tree and ending in the inside. After the olives were harvested, the fruit samples were immediately transported in ventilated storage trays to the Abencor system pilot plant, located in the Chemistry Faculty, to avoid alterations to the fruits.

\subsubsection{Determination of Olive RI}

RI was determined according to a classification based on fruit colour of both the skin and pulp as described in "Método de Índice de Madurez" (Uceda \& Frías, 1975). Olives were classified as green (G) when their RIs were lower than 2.0, medium (M) for values between 2.0 and 3.0, and ripe $(\mathrm{R})$ for values above 3.0, as described by Franco et al. (2015) for qualifying olives.

\subsubsection{VOO Extraction Using the Laboratory Plant System Abencor and Yield Determination}

VOO extraction from collected olives was conducted at the Facultad de Química laboratory plant within $24 \mathrm{~h}$ of harvest as suggested by Aguilera, G. Beltrán, Sánchez-Villasclaras, Uceda, \& A. Jiménez (2010), B. Jiménez et al. (2013), and Reboredo-Rodríguez et al. (2015).

The extraction conditions were as follows: the sieve size from the hammer mill was $5 \mathrm{~mm}$ and olives were crushed at $3000 \mathrm{rpm}$. Previous studies (Ellis, 2016) showed that Uruguayan olive pastes from the Arbequina variety have a moisture level higher than 50\%, designating them as "difficult pastes" (Aguilera et al., 2010). To ease the separation between the oil and other compounds of olive paste and, as a result, increase extraction yield by depleting the subproducts, micronized natural talc (MNT) was added to the olive paste during the malaxation stage as a technological coadjuvant at 2.3\% (Alba, 2008; Aguilera et al., 2010). The MNT was used in all extractions performed during the two years of the study. The paste with the talc was malaxated (using a 
thermostatic olive paste mixer) for $50 \mathrm{~min}$ at $30^{\circ} \mathrm{C}$; in the middle of this process, $200 \mathrm{~mL}$ of water was added.

After the malaxation stage, the content of each of the eight vessels from the thermostatic olive paste mixer were centrifuged in an Abencor vertical centrifuge at $3500 \mathrm{rpm}$ for $1 \mathrm{~min}$.

The extracted oil was stored under protection from light in amber-coloured glass bottles at $4^{\circ} \mathrm{C}$ until analysis.

The yield obtained from the extraction process at the Abencor plant was calculated according to Criado, Motilva, Goñi, \& Romero, (2007). Moisture values were expressed as an oil percentage.

\subsubsection{Olive Moisture Determination}

The moisture content of the olives was determined by gravimetric analysis. Twenty grams of the homogeneous olive paste with the stone, which was freshly milled using the hammer mill of the Abencor system, were weighed in glass Petri dishes and dried in a conventional oven at $105^{\circ} \mathrm{C}$ for $12 \mathrm{~h}$. The weight decrease was expressed as the moisture percentage according Reboredo-Rodríguez et al. (2015).

\subsubsection{Olive Oil Yield Determination by Soxhlet Method}

To determine olive oil yield, expressed as the percentage content of oil in olive paste according to UNE 55030, IUPAC Method 1.11, olives were milled with the stone using the Abencor system hammer mill. The fresh olive paste was desiccated in a conventional oven at $105^{\circ} \mathrm{C}$ for $12 \mathrm{~h}$, and the oil was extracted in a Soxhlet apparatus using petroleum ether $\left(62-68^{\circ} \mathrm{C}\right.$ boiling point) as a solvent. The system was brought to a boil and extraction was performed or $8 \mathrm{~h}$, after which the solvent was removed and the yield was determined as dry matter weight (\% dry weight) and wet matter weight (\% wet weight).

\subsection{Quality Chemical Parameters}

\subsubsection{Free Acidity Determination}

Free acidity (FA) was determined according to IOC recommendations using ISO 660 "Determination of degree of acidity and free acidity". Free acidity was expressed as the percentage of oleic acid.

\subsection{Chemical Characterisation of EVOO}

\subsubsection{EVOO Total Polyphenol Content Determination}

Total polyphenol content in EVOO was determined according to the IOC method/T 20/Doc No29 November 2009: "Determination of biophenols in olive oils by HPLC". Syringic acid was used as internal standard.

An HPLC Shimadzu 20 A was used along with a diode array detector (model SPD-M20A) and C18 Phenomenex column (4.6 mm diameter, $25 \mathrm{~cm}$ long, $5 \mu \mathrm{m}$ particle size). Phenolic compounds were quantified at a wavelength of $280 \mathrm{~nm}$ using water with $0.2 \% \mathrm{H}_{3} \mathrm{PO}_{4}$ [V/V] /methanol/acetonitrile 96/2/2 [V/V/V] as the mobile phase as recommended by IOC 2009 . The external calibration standards were tyrosol and syringic acid.

Before total polyphenol content determination by HPLC, extraction was performed using $2.0 \mathrm{~g}$ of EVOO. A methanol/water 80/20 (V/V) solution was used for extraction, along with the addition of syringic acid solution.

\subsubsection{EVOO Total Tocopherol Content Determination}

For total tocopherol determination in EVOO, the method proposed by Andrikopoulos, Brueschweiler, Felber, \& Taeschler, (1991): "HPLC analysis of phenolic antioxidants, tocopherols and triglycerides" was used. Thirty milligrams of EVOO were weighed and dissolved in $1 \mathrm{~mL}$ isopropanol. Calibration curves were developed using $\alpha$-tocopherol, $\gamma$-tocopherol, and $\delta$-tocopherol standards (Sigma-Aldrich, St. Louis, MO, USA). An HPLC Shimadzu 20A was used, along with a fluorescence detector (Shimadzu RF 20A XS) set to a $290 \mathrm{~nm}$ excitation wavelength and $330 \mathrm{~nm}$ emission wavelength, as well as the PDA detector described above. The oven was maintained at $35^{\circ} \mathrm{C}$.

\subsubsection{EVOO Fatty Acid Composition Determination}

The fatty acid composition of EVOO was determined by gas chromatography with previous derivatisation of the oil into fatty acid methyl esters according to IOC/T.20/Doc. N'24, 2001 "Preparation of fatty acid methyl esters from olive oil and olive pomace oil". Method A: "Cold transesterification with potassium hydroxide methanolic solution" was conducted, followed by IOC, 2015: "Gas chromatography analysis of fatty acid methyl esters" Method AOACS Ch 2-9. IOC/T.20/Doc No 33 February 2015 "Determination of fatty acid methyl esters by gas chromatography".

\subsection{Sensory Characterisation of EVOO}

Samples were evaluated by a panel of 10 trained panellists belonging to the olive oil sensory panel at the Faculty 
of Chemistry, which has been approved by the IOC since 2012. The IOC official method IOC/T.20/Doc $\mathrm{N}^{\circ} 15 / \mathrm{Rev} .8 / 2015$ was applied, along with a descriptive tasting, to evaluate the following descriptors: green (olive leaf, herb, grassy), fig, tomato (plant, leaf, fruit), apple, banana (peel, fruit), nut/almond, sweet, astringent, and other positive attributes.

The intensity of these attributes was evaluated using a linear, non-structured scale ranging from 0 to $10 \mathrm{~cm}$ and from "nothing" to "very" as extremes. Furthermore, the "fruity" attribute was described by the evaluator as either "green" or "mature", if perceived.

Samples were served in normalized blue cups $(15 \mathrm{~mL})$, codified with a letter and two random numbers, at a temperature of de $28 \pm 2{ }^{\circ} \mathrm{C}$. Each sample was evaluated in duplicate. Green apple, natural yoghurt, room temperature water, and crackers were used as erasers.

\subsection{Statistical Analysis}

All chemical analyses were performed in triplicate.

Analysis of variance was performed on chemical and sensory data considering year, RI, and the interaction year $\times$ RI as variation factors. Mean ratings and honestly significant differences were determined, based on Tukey's test $(\mathrm{p}<0.05)$. All statistical analyses were performed using XL-Stat 2017 software (Addinsoft, New York, NY, USA).

\section{Results and Discussion}

\subsection{Olive Properties}

In 2015, olives were harvested during April to obtain 14 samples of EVOO, which presented different RI values: 4 were green, 4 were medium, and 6 were ripe.

In 2016, olives were collected between March and April to obtain 14 samples of EVOO with various RI values: 5 were green, 5 were medium, and 4 were ripe. Thus, during the two years of study, 28 samples of EVOO were obtained.

Producers typically estimate the best harvest time according to the olives' RI, which is calculated based on the colour of the fruit in the olive tree. The aim of this study was to determine the oil content in different RI stages for two years. The results were expressed as yield of dry and wet materials, both as percentages. Additionally, yield was measured using the Abencor System. The results are shown in Table 1.

Olive moisture content was significantly affected by the year $(\mathrm{p}=0.0012)$, as was the yield determined with the Abencor $(p<0.0010)$ and yield of dry materials $(p=0.0297)$. In 2015, the moisture content of oil was significantly higher than in 2016, likely because of the high rainfall which occurred during the months before harvest. Rainfall during February and March was $350 \mathrm{~mm}$ in 2015, while in the following year during the same months, rainfall was of $200 \mathrm{~mm}$ (INIA, 2017). This affected the Abencor yield, which was significantly lower in 2015, as shown in Table 1.

Moisture and yield based on wet weight were not affected by the olive's stage of maturity. However, the Abencor yield and yield based on dry weight were significantly higher for ripe olives than for green olives. Franco et al. (2015) suggested that this increase was caused by water evaporation from ripe olives, while lipid biosynthesis slowly continued. Yield based on dry weight is a more reliable parameter for comparison than yield based on wet weight, as the latter is strongly influenced by the olive's moisture. 
Table 1. Results of the olive properties

\begin{tabular}{|c|c|c|c|c|c|}
\hline \multirow[t]{3}{*}{ YEAR } & \multirow{3}{*}{$\begin{array}{l}\text { RIPENING } \\
\text { INDEX (RI) }\end{array}$} & \multicolumn{4}{|c|}{ Olive fruit properties } \\
\hline & & MOISTURE & ABENCOR SYSTEM & OIL YIELD (\% & OIL YIELD $(\%$ \\
\hline & & $(\%)$ & YIELD (\%) & WET WEIGHT) & DRY WEIGHT) \\
\hline \multirow{4}{*}{2015} & G & $62.6^{\mathrm{a}}$ & $9.7^{\mathbf{a}}$ & $15.1^{\mathrm{a}}$ & $37.0^{\mathbf{a}}$ \\
\hline & M & $63.8^{\mathbf{a}}$ & $10.0^{\mathbf{a}}$ & $16.1^{\mathrm{a}}$ & $40.3^{\mathbf{a}, \mathbf{b}}$ \\
\hline & $\mathrm{R}$ & $62.5^{\mathrm{a}}$ & $11.6^{\mathbf{b}}$ & $18.0^{\mathbf{a}}$ & $43.5^{\mathbf{b}}$ \\
\hline & $\mathrm{p}$ value & 0.7857 & 0,0219 & 0,3177 & 0,0196 \\
\hline \multirow{3}{*}{ YEAR } & RIPENING & MOISTURE & ABENCOR SYSTEM & OIL YIELD (\% & OIL YIELD $(\%$ \\
\hline & INDEX (RI) & $(\%)$ & YIELD (\%) & WET WEIGHT) & DRY WEIGHT) \\
\hline & G & $57.8^{\mathbf{a}}$ & $12.3^{\mathrm{a}}$ & $15.9^{\mathrm{a}}$ & $35.1^{\mathrm{a}}$ \\
\hline \multirow[t]{3}{*}{2016} & M & $60.0^{\mathbf{a}}$ & $12.5^{\mathrm{a}}$ & $15.1^{\mathrm{a}}$ & $38.5^{\mathbf{a}, \mathbf{b}}$ \\
\hline & $\mathrm{R}$ & $58.9^{\mathbf{a}}$ & $13.5^{\mathbf{b}}$ & $16.0^{\mathrm{a}}$ & $39.5^{\mathbf{b}}$ \\
\hline & $\mathrm{p}$ value & 0.3549 & 0.0034 & 0.7384 & 0.0425 \\
\hline
\end{tabular}

Different letters in the same column denote significant statistical differences al $\mathrm{p}<0.05$ (Tukey's test) among ripening index in each year.

While Franco et al. (2015) reported that olive moisture depends on the fruit's ripeness stage, these results do not agree with those found in this study, in which RI did not significantly affect the olive moisture.

Aguilera et al. (2010) characterised olive pastes with moisture higher than 50\% as difficult pastes. Particularly, these authors determined the moisture content of paste obtained from Picual olives and characterized it as "very difficult paste", with a moisture value of $56.3 \%$. For difficult pastes, larger and stronger emulsions are formed during the milling phase, which are impossible to break under malaxation conditions. The moisture content of the olives analysed in this work revealed that the resulting pastes were "very difficult pastes", which may explain the low yield obtained from the studied harvests, compared to yields obtained from Arbequina in other countries, as reported by Reboredo-Rodríguez et al. (2015).

\subsection{Chemical Quality Parameters}

The free acidity percentage is a direct measure of olive oil quality and represents the extent of hydrolytic activities reflecting the care taken from blossoming and fruit set to eventual sale and consumption of the oil (Reboredo-Rodríguez et al., 2016). The results are shown in Table 2. The harvest year significantly influenced free acidity ( $<0.0001$ ), with the 2016 oils showing higher values (expressed as percentage oleic acid) than the 2015 oils, as reported by Rodrigues et al. (2018). For the 2015 harvest, free acidity significantly differed between the different RI values ( $p<0.0001)$, with an increase from green to ripe RI. Franco et al. (2015) found that the values of free acidity for Arbequina increased as the RI increased. The authors predicted that EVOOs obtained from olives with higher RI had higher percentages of free acidity because of their increased enzymatic activity, particularly lipolytic enzymes, and increased sensitivity to mechanical damage and pathogen infections. This trend was not confirmed for the 2016 harvest, in which no significant differences were found in the free acidity of different RI olives (Table 2).

All analysed oil samples showed free acidity values lower than $0.8 \%$, which is the upper limit established by the IOC (IOC/T.15/NC No 3/Rev.8, 2015, and successive revisions) for an oil to be categorised as EVOO; this demonstrates that the olives used in the present study were in good condition at the time of oil extraction and that the extraction itself and subsequent storage were effectively performed (Rodrigues et al., 2018).

\subsection{Chemical Characterisation of EVOO}

\subsubsection{Polyphenols}

Phenolic compounds are considered as natural antioxidants responsible for oil stability through oxidation and contribute to sensory characteristics, such as bitterness and pungent flavours (Reboredo-Rodríguez et al., 2016). According to B. Jiménez et al. (2013), during the fruit ripening process, a series of metabolic processes occurs (chemical and enzymatic reactions), resulting in the production of free phenols and induction of variations in the phenolic profile of several compounds. These changes affect the quality, sensory properties, oxidative stability, and/or nutritional value of the obtained oil.

Table 2 presents the total polyphenol content, expressed in \% syringic acid. The harvest year significantly influenced these values $(\mathrm{p}=0.0386)$, with the values for 2015 lower than those for 2016 . This may be related to the amount of rainfall in 2015, as explained in item 3.1, which is consistent with the moisture values for this 
harvest year.

According to Katsoyannos et al. (2015), as the ripeness index increases, the total contents of tocopherols and polyphenols decrease. This was not observed in the present study, as the RI did not significantly affect $(\mathrm{p}>0.05)$ the polyphenol content in either harvest year evaluated.

Reboredo-Rodríguez et al. (2015) reported that the total polyphenol content for the Arbequina variety, with an RI of 3.3, was $162 \mathrm{ppm}$ in Galicia, Spain. Values obtained for Uruguayan oils were similar for the 2015 harvest year and higher for the 2016 harvest year.

\subsubsection{Tocopherols}

According to Reboredo-Rodríguez et al. (2016), tocopherols are the main lipid-soluble antioxidants present in EVOO. Four isomers can be found in $\operatorname{EVOO}(\alpha, \beta, \gamma$, and $\delta$ ), with $\alpha$-tocopherol (Vitamin E) as the most abundant. Table 2 lists the obtained values for tocopherols in this study. There was no significant difference in total tocopherol content for different RI values and for different harvest years $(\mathrm{p}=0.2465)$.

Velasco et al. (2015) found that the total tocopherol normal range in VOO is $100-250 \%$; for the Arbequina variety from the Cabra region in Spain, the authors reported a concentration of $148 \%$ as the median RI. Values found in this study were higher than those for both harvest years and for all studied RI values.

\subsubsection{Fatty Acid Composition}

The main fatty acid composition of EVOO is shown in Table 2; the RI was significantly influenced by linoleic acid in the 2015 harvest and by palmitic, oleic, and linoleic acid in the 2016 harvest. The harvest year significantly influenced the contents of stearic $(p=0.0192)$, linoleic $(p<0.0001)$, and linolenic $(p=0.0158)$ acids, which were higher in 2015, while oleic acid was higher ( $\mathrm{p}<0.0001)$ in 2016.

The highest fatty acid percentage was obtained for oleic acid, followed by palmitic, linoleic, and stearic acids; this as agrees with the results reported by Reboredo-Rodríguez et al. (2016). The same authors reported that the Spanish Arbequina variety is characterised by its high linolenic acid content (12.57-13.06\%) and low oleic content (68.20-65.83\%). This agrees with the results of the current study for the 2015 harvest, but not with the results obtained for the 2016 harvest, in which higher values of oleic acid and lower values for linoleic acid were obtained compared to the previous study.

According to studies carried out by Buffa, Tropea, Mattar, Carelli, \& Ceci (2013) and Katsoyannos et al. (2015), as the RI of olives increases, the relationship between percentages of oleic/linoleic acid found in the oil decreases. This trend agrees with the results obtained in this study for both harvest years, as shown in Table 2 .

Borges et al. (2017) evaluated Arbequina VOO in Australia, Argentina, and Tunisia and found that different cultivation and environmental conditions strongly affect the fatty acid composition of VOO, with oleic and palmitic acids most strongly affected. In addition to the geographical and climate conditions considered in these studies, other factors such as RI, storage conditions, processing conditions, and other environmental factors (light intensity, relative humidity, and evapo-transpiration) may influence the chemical composition of VOO.

All studied fatty acid values were within the limits established by the IOC for EVOOs. 

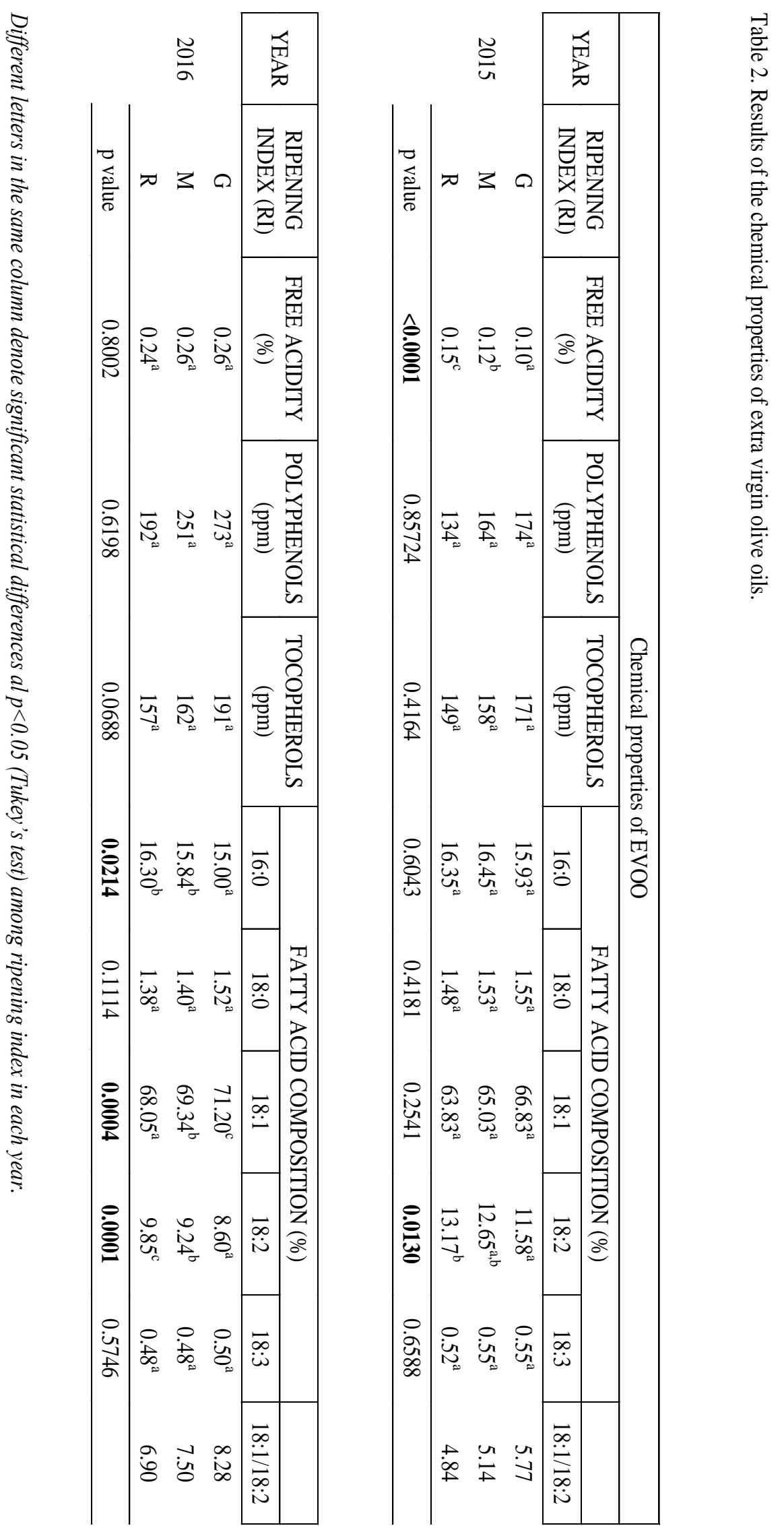


\subsection{Sensory Characterisation of EVOO}

For the data obtained from the sensory panel for the 28 samples of VOO, the median and robust coefficient of variation were calculated for each attribute (positive and negative) according to IOC regulations. According to the results, all VOOs were classified as EVOOs because the defect median was zero and fruity attribute median was higher than zero in all samples.

In the evaluated samples, the sensory panel perceived the attributes fruity, bitter, pungent, green, banana, nut, sweet, and astringent, as is shown in Table 3. According to the analysis of variance results, the interaction year $\times$ RI studied were not significant ( $p>0.05$ ), making it possible to study the effect of each factor independently.

The harvest year significantly affected the intensities of the fruity $(\mathrm{p}<0.0010)$, bitter $(\mathrm{p}<0.0010)$, pungent $(\mathrm{p}<$ $0.0001)$, green $(p<0.0010)$, banana $(p=0.0108)$, sweet $(p=0.0001)$, and astringent $(p=0.0001)$ attributes. As shown in Table 3, 2016 oils had higher intensities of fruity, bitter, pungent, green, banana, and astringent attributes and lower intensity of the sweet attribute. The sensory results were correlated with higher moisture content and a lower polyphenol content in the oils was obtained for the 2015 harvest.

Sensory qualities of VOO are affected by the presence of specific minor compounds, among which phenolic and volatile compounds are the most important. Phenolic compounds are responsible for flavour characteristics such as bitterness, kinesthetic sensations such as pungency, and exhibit antioxidant activity, which is widely responsible for the oxidative stability, shelf life, and nutritional value of VOO (Lukić et al., 2017; Xiang et al., 2017). In the present study, the relationship between sensory characteristics and polyphenol content was confirmed in the studied samples, as the presence of phenolic compounds stimulates taste receptors and the trigeminal nerve, evoking the sensations of bitterness in the first case and pungency and astringency in the second case. Low-weight volatile compounds easily evaporate at room temperature and, following stimulation of nasal receptors, are responsible for the VOO characteristic aroma (De Santis \& Frangipane, 2015).

For the 2015 harvest oils, for higher RI values, a significant decrease $(\mathrm{p}<0.05)$ was observed in the bitter, pungent, and green attributes, while an increase was observed for the sweet attribute $(p<0.05)$. For the 2016 harvest oils, an increase in RI resulted in a significant decrease $(\mathrm{p}<0.05)$ in the pungent, green, and astringent attributes, as shown in Table 3. These results agree with the information reported by B. Jiménez et al. (2013) and Franco et al. (2015), who determined that the bitter, pungent, and green attributes decreased in intensity as the sweet attribute and the olives' RI increased.

The sensory profile of Uruguayan olive oils of the Arbequina variety coincided with reports by other authors for the same olive variety in other regions of the world, who found that these oils have a medium fruity attribute and mild bitter and pungent attributes. Franco et al. (2015) characterised oils obtained from seven different varieties from plantations in southwestern Spain and concluded that oils from the Arbequina variety presented the lowest values for the fruity and pungent attributes. Aparicio \& Harwood (2003) used the sensory descriptors soft, slightly pungent, and medium green aroma to characterise this variety. B. Jiménez \& Caprio (2008) reported that this oil presents a fruity aroma reminiscent of olives and other fruits, with fluid, sweet, and nearly imperceptible bitterness and pungency; these attributes make the variety particularly suitable for consumers not accustomed to the taste and aroma of virgin olive oils. 


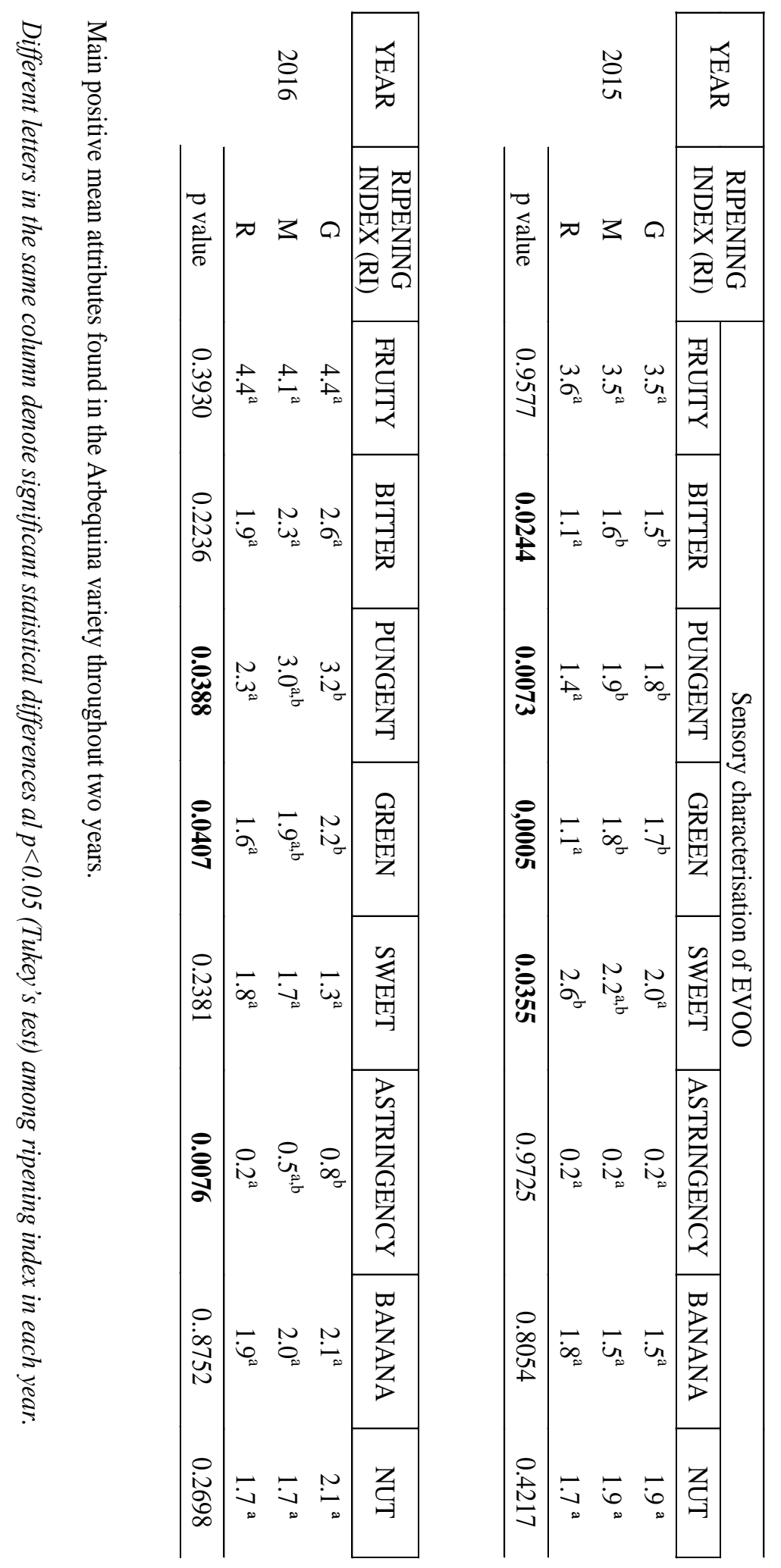

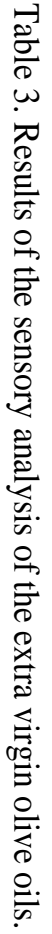




\section{Conclusions}

The chemical analysis results and sensory profiles of the 28 samples revealed that all oils examined belonged to the EVOO category according to IOC regulations.

Fruit moisture is an important parameter that must be considered, as olives with higher water content typically have a lower oil yield, which also negatively affects the quality of the oil obtained.

For olive physical and chemical properties, the RI significantly affected different parameters depending on the harvest year.

All pastes studied were considered "difficult pastes" because of the high moisture content in the olives; this should be considered by producers when determining the optimal harvest time, to achieve a balance between yield (which is significantly greater in olives with an RI above 3) and oil quality. At higher RI, sensory aspects, such as bitter and pungency decrease along with the content of antioxidants, such as polyphenols.

\section{References}

Alba, J. (2008). Elaboración del aceite de oliva virgen. In: El cultivo del olivo. (Barranco, D., Fernández-Escobar, R., Rallo, L.) 6ta Ed. Ediciones Mundi-Prensa, Madrid, España. pg. 657-697.

Aguilera, M. P., Beltrán, G., Sánchez-Villasclaras, S., Uceda, M., \& Jiménez, A. (2010). Kneading olive paste from unripe "Picual" fruits: I. Effect on oil process yield. Journal of Food Engineering, 97, 533-538. http://dx.doi.org/ 10.1016/j.jfoodeng.2009.11.013

Amelio, M. (2016). The official method for olive oil sensory evaluation: An expository revision of certain sections of the method and a viable means for confirming the attribute intensities. Trends in Food Science \& Technology, 47, 64-68. http://dx.doi.org/10.101016/j.tifs.2015.11.001

Andrikopoulos, N. K., Brueschweiler, H., Felber, H., \& Taeschler, Ch. (1991). HPLC analysis of phenolic antioxidants, tocopherols and triglycerides. Journal of the American Oil Chemists' Society, 68, 359-364. https://doi.org/10.1007/BF02663750

Aparicio, R., \& Harwood, J. (2003). Manual del aceite de oliva. AMV Ediciones, Madrid, España.

ASOLUR (Asociación Olivícola Uruguaya), 2017. Retrieved from http://www.asolur.org.uy/s/es/search

Beltrán, M., Sánchez-Astudillo, M., Aparicio, R., \& García, G. D. L. (2015). Geographical traceability of virgin olive oils from south-western Spain by their multi-elemental composition. Food Chemistry, 169, 350-357. http://dx.doi.org/10.1016/j.foodchem.2014.07.104

Borges, T. H., Pereira, J. A., Cabrera-Vique, C., Lara, L., Oliveira, A. F., \& Seiquer, I. (2017). Characterization of Arbequina virgin olive oils produced in different regions of Brazil and Spain: Physicochemical properties, oxidative stability and fatty acid profile. Food Chemistry, 215, 454-462.

https://doi.org/10.1016/j.foodchem.2016.07.162

Buffa, M. A., Tropea, G., Mattar, S., Carelli, A., \& Ceci, L. (2013). Análisis químico y sensorial de aceites de oliva de la provincia de San Juan (Argentina). XVI simposio científico-técnico del aceite de oliva, Expoliva.- Jaén, España.

Civantos, L. (2008). La olivicultura en el mundo y en España. In: El cultivo del olivo. (Barranco, D., Fernández-Escobar, R. Rallo, L.) 6ta Ed. Ediciones Mundi-Prensa, Madrid, España. pg. 17-35.

Criado, M. N., Motilva, M. J., Goñi, M., \& Romero, M. P. (2007). Comparative study of the effect of the maturation process of the olive fruit on the chlorophyll and carotenoid fractions of drupes and virgin oils from Arbequina and Farga cultivars. Food Chemistry, 100, 748-755. http://dx.doi.org/10.1016/j.foodchem.2005.10.035.

De Santis, D., \& Frangipane, M.T. (2015). Sensory Perceptions of Virgin Olive Oil: New Panel Evaluation Method and the Chemical Compounds Responsible. Natural Science, 3, 132-142. http://dx.doi.org/10.4236/ns.2015.73015

Ellis, A. C. (2016). Calidad sensorial y fisicoquímica de aceite de oliva nacional variedad Arbequina y Picual (Doctoral dissertation). University of the Republic, Scholl of Chemistry, Montevideo, Uruguay.

Franco, M. N., Sánchez, J., De Miguel, C., Martínez, M., \& Martín-Vertedor, D. (2015). Influence of the Fruit's Ripeness on Virgin Olive Oil Quality. Journal of Oleo Science, 64(3), 263-273. http://dx.doi.org/10.5650/jos.ess 14148

García-González, D. L., Romero, N., \& Aparicio, R. (2010). Comparative study of virgin olive oil quality from 
single varieties cultivated in Chile and Spain. Journal of Agricultural and Food Chemistry, 58(24), 12899-12905. https://doi.org/10.1021/jf1031313

INIA (Instituto Nacional de Investigación Agropecuaria), 2017. Retrieved from http://www.inia.uy

IOC (International Olive Council), 2017. Retrieved from http://www.internationaloliveoil.org

IOC (2015). Chemistry/TestingMethods/Chemical testing methods.

Jiménez, B., \& Carpio, A. (2008). La cata de aceites: aceite de oliva virgen. Características organolépticas y análisis sensorial. Edita: Junta de Andalucía. Instituto de Investigación y Formación Agraria y Pesquera, Consejería de Agricultura y Pesca, Spain

Jiménez, B., Sánchez-Ortiz, A., Lorenzo, M. L., \& Rivas, A. (2013). Influence of fruit rippening on agronomic parameters, quality indices, sensory attributes and phenolic compounds of Picudo olive oils. Food Research International, 54, 1860-1867. http://dx.doi.org/10.1016/j.foodres.2013.08.016

Katsoyannos, E., Batrinou, A., Chatzilazarou, A., Bratakos, S. M., Stamatopoulos, K., \& Sinanoglou, V. J. (2015). Quality parameters of olive oil from stoned and nonstoned Koroneiki and Megaritiki Greek olive varieties at different maturity levels. Grasas Aceites, 66(1), e067. http://dx.doi.org/10.3989/gya.0711142.

Lukić, I., Žanetić, M., Špika, M. J., Lukić, M., Koprivnjak, O., \& Bubola, K. B. (2017). Complex interactive effects of ripening degree, malaxation duration and temperatura on Oblica cv. Virgin olive oli phenols, volatiles and sensory quality. Food Chemistry, 232, 610-620. http://dx.doi.org/10.1016/j.food.chem.2017.04.047

Navarro, C., \& Parra, M. A. (2008). Plantación. In: El cultivo del olivo. (Barranco, D., Fernández-Escobar, R., Rallo, L.) 6ta Ed. Ediciones Mundi-Prensa, Madrid, España. pg. 189-238.

Rapoport, H. F. (2008). Botánica y morfología. In: El cultivo del olivo. (Barranco, D., Fernández-Escobar, R., Rallo, L.) 6ta Ed. Ediciones Mundi-Prensa, Madrid, España. pg. 39-61

Reboredo-Rodríguez, P., González Barreiro, C., Cancho-Grande, B., Valli, E., Bendini, A., Gallina, T., T., \& Simal-Gandara, J. (2016). Characterization of virgin olive oils produced with autochthonous Galician varieties. Food Chemistry, 212, 162-171. http://dx.doi.org/10.1016/j.foodchem.2016.05.135.

Reboredo-Rodríguez, P., Gonzalez-Barreiro, C., Cancho-Grande, B., Fregapane, G., \& Salvador, M. (2015). Characterisation of extra virgin olive oils fron Galician autochthonous varieties and their co-crushings with Arbequina and Picual cv. Food Chemistry, 176, 493-503. http://dx.doi.org/10.1016/jfoodchem.2014.12.078

Rodrigues, N., Casal, S., Peres, A. M., Baptista, P., Bento, A., Martín, H., Asensio-S-Manzanera, M. C., \& Pereira, J. A. (2018). Effect of olive tres density on the quality and composition of olive oil from cv. Arbequina. Scientia Horticulturae, 238, 222-233. http://dx.doi.org/10.1016/j.scienta.2018.04.059

Romero, N., Saavedra, J., Tapia, F., Sepúlveda, B., \& Aparicio, R. (2016). Influence of agroclimatic parameters on phenolic and volatile compounds of Chilean virgin olive oils and characterization based on geographical origin, cultivar and ripening stage. Journal of the Science of Food and Agriculture, 96(2), 583-592. https://doi.org/10.1002/jsfa.7127

Rondanini, D. P., Castro, D. N., Searles, P. S., \& Rousseaux, M. C. (2014). Contrasting patterns of fatty acid composition and oil accumulation during fruit growth in several olive varieties and locations in a non-Mediterranean region. European Journal of Agronomy, 52, 237-246. https://doi.org/10.1016/j.eja.2013.09.002

Rondanini, D., Castro, D., Searles, P., \& Rousseaux, M. (2011). Fatty acid profile or varietal virgin olive oils (Olea europaea L.) from mature orchards in warm arid valleys of Northwestern Argentina (La Rioja). Grasas Aceites, 62(4), 399-409. http://dx.doi.org/10.3989/gya.125110

Torres, M. M., Pierantozzi, P., Cáceres, M. E., Labombarda, P., Fontanazza, G., \& Maestri, D. M. (2009). Genetic and chemical assessment of Arbequina olive cultivar grown in Córdoba province, Argentina. Journal of the Science of Food and Agriculture, 89(3), 523-530. https://doi.org/10.1002/jsfa.3483

Uceda, M., \& Frías, L. (1975). Trend of the quality and quantitive composition of olive fruit oil during ripening. Proceedings of the International Meeting on Olive Oil. 25-46. Córdoba, Spain.

URUGUAY XXI. (2013) Sector Olivícola. Promoción de Inversiones y Exportaciones. Presidencia de la República Oriental del Uruguay. Retrieved from http://www.uruguayxxi.gub.uy/exportaciones/wp-content/uploads/sites/2/2014/09/Sector-Olivicola-Dec-201 
3-Uruguay-XXI.pdf.

Velasco, L., De la Rosa, R., \& León, L. (2015). Advanced olive selections with enhanced quality for minor constituents. Grasas Aceites, 66(4), 1-7. http://dx.doi.org/10.3989/gya.0227151.

Villamil, J., \& Conde, P. (2013). Variedades. In: Aceites de oliva: de la planta al consumidor. Vol. 1 (Grompone, M. A.; Villamil, J.) Ed. Hemisferio Sur. Montevideo, Uruguay.

Xiang, C., Xu, Z., Liu, J., Li, T., Yang, Z., \& Ding, C. (2017). Quality, composition, and antioxidant activity of virgin olive oil from introduced varieties al Liangshan. Food Science and Technology, 78, $226-234$. http://dx.doi.org/10.1016/j.lwt.2016.12.029

Yousfi, K., Weiland, C. M., \& García, J. M. (2013). Responses of fruit physiology and virgin oil quality to cold storage of mechanically harverest "Arbequina" olives cultivated in hedgerow. Grasas Aceites, 64(5), 572-582. http://dx.doi.org/10.3989/gya.063013

Youssef, N. B., Zarrou, K. W., Carrasco-Pamcorbo, A., Ouni, Y., Segura-Carretero, A., ... Fernández-Gutiérrez, A. (2010). Effect of olive rippeness on Chemicals propierties and phenolic composition of Chetoui virgin olive oil. Journal of the Science of Food and Agriculture, 90, 199-204. http://dx.doi.org/10.1002/jsfa.3784

\section{Copyrights}

Copyright for this articleis retained by the author(s), with first publication rights granted to the journal.

This is an open-access article distributed under the terms and conditions of the Creative Commons Attribution license (http://creativecommons.org/licenses/by/4.0/). 